\title{
An investigation on the role of organizational climate on organizational citizenship behavior
}

\author{
Mahsan Hajirasouliha, Elham Agha Alikhani, Ashkan Faraji, Saba Kamali, Hosseinali Aziziha and \\ Seyed Shahab Mousavi*
}

Department of Management and Accounting, South Branch, Islamic Azad University, Tehran, Iran

CH R O I C L E A B T R A T

Article history:

Received July 28, 2013

Received in revised format

20 November 2013

Accepted 4 January 2014

Available online

February 72014

Keywords:

Organizational climate

Organizational citizenship

behavior

Sipa Group

\begin{abstract}
This paper presents an empirical study to investigate the effect of organizational climate on organizational citizenship behavior in one of Iranian automakers. The proposed study uses a standard questionnaire for measuring organizational citizenship behavior, which is adopted from Podsakoff et al. (2000) [Podsakoff, P. M., MacKenzie, S. B., Paine, J. B., \& Bachrach, D. G. (2000). Organizational citizenship behaviors: A critical review of the theoretical and empirical literature and suggestions for future research. Journal of management, 26(3), 513563.]. The study also uses another questionnaire, which measures organizational climate, which is adopted from Arabac1 (2010) [Arabac1, I. B. (2010). Academic and administration personnel's perceptions of organizational climate (Sample of Educational Faculty of Firat University). Procedia-Social and Behavioral Sciences, 2(2), 4445-4450.] and both questionnaires are designed in Likert scale. Cronbach alphas for organizational citizenship behavior and organizational climate are measured as 0.78 and 0.84 , respectively, which are above the acceptance level of 0.70 . Therefore, we can confirm the validity of both questionnaires. The study is implemented among 200 experts in Iranian automaker, randomly and using Spearman correlation ratio as well as stepwise regression techniques, the study has detected a meaningful relationship between components of organizational climate and organizational citizenship behavior.
\end{abstract}

\section{Introduction}

During the past few years, there have been growing interests in investigating various factors influencing organizational citizenship behavior (Raub, 2008; Matiaske \& Weller, 2007). Chiang and Hsieh (2012) studied the effects of perceived organizational support and psychological empowerment on job performance by looking into the mediating impacts of organizational citizenship behavior. They reported that perceived organizational support and psychological empowerment positively influenced organizational citizenship behavior. However, perceived organizational support

*Corresponding author

E-mail addresses: moosavi.shahab@ymail.com (S. S. Mousavi) 
did not positively affect job performance. While psychological empowerment and organizational citizenship behavior positively impacted job performance, organizational behavior acted as a partial mediator between perceived organizational support and job performance. Koster and Sanders (2006) aimed at contributing to the debate on organizational citizenship behavior (OCB) by developing a theory-driven measure of cooperative behavior within organizations, called organizational solidarity (OS) and recommended that supervisors could play a facilitating role in creating and sustaining cooperative behavior of employees.

Korkmaz and Arpac1 (2009) investigated the relationship between organizational citizenship behavior and emotional intelligence and reported that emotional intelligence of the organizational citizenship behavior of followers. Organ and Ryan (1995) performed a meta-analttic review of attitudinal and dispositional predictors of organizational citizenship behavior. Allen (2003) investigated organizational climate and strategic change in higher education and discussed how a change on educational climate could make changes on educational development.

Boiral (2009) performed an investigation on the pertinence of organizational citizenship behaviors in improving the efficacy of environmental management. They explained how the principal dimensions of these behaviors could be used to the environmental practices of organizations and underlined their importance in responding to essential challenges of environmental management, including the complexity of environmental issues, limitations of formal management systems. Chiaburu and Baker (2006) investigated the antecedents of taking charge, an extra-role behavior (ERB) directed at challenging the status-quo. They found some support for the distinctiveness of taking charge, a kind of ERB, which challenges the status-quo, from traditional ERB. Wang and Ahmed (2004) performed an investigation on the development and validation of the organizational innovativeness construct using confirmatory factor analysis. They identified five dimensions of an organization's overall innovativeness through an extensive literature review and these five dimensions formed the component factors of the organizational innovativeness construct.

\section{The proposed study}

This paper presents an empirical study to investigate the effect of organizational climate on organizational citizenship behavior in one of Iranian automakers named Saipa. The proposed study uses a standard questionnaire for measuring organizational citizenship behavior, which is adopted from Podsakoff et al. (2000). The study also uses another questionnaire, which measures organizational climate, which is adopted from Arabac1 (2010) and both questionnaires are designed in Likert scale. There were 42 questions associated with the proposed study of this paper where 4 questions are associated with risk taking, 5 questions covered organizational commitment, 4 questions were related to reward and promotion, 6 questions were associated with team-work, 3 questions studied organizational structure, 4 questions are related to organizational communication and 3 questions were associated with organizational conflict. The sample size is calculated as follow,

$$
n=\frac{N \times z_{\alpha / 2}^{2} \times p \times q}{\varepsilon^{2} \times(N-1)+z_{\alpha / 2}^{2} \times p \times q},
$$

where $N$ is the population size, $p=1-q$ represents the yes/no categories, $z_{\alpha / 2}$ is CDF of normal distribution and finally $\varepsilon$ is the error term. Since we have $p=0.5, z_{\alpha / 2}=1.96$ and $N=350$, the number of sample size is calculated as $n=152$. We have distributed 200 questionnaires among some experts in automaker of the proposed study. In our suvey, $72.94 \%$ of the participants were male and $27.06 \%$ of them were female. Fig. 1 shows details of other personal characteristics of the participants. 


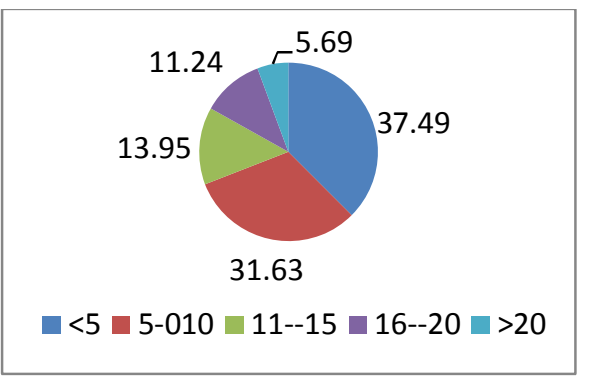

Years of experience

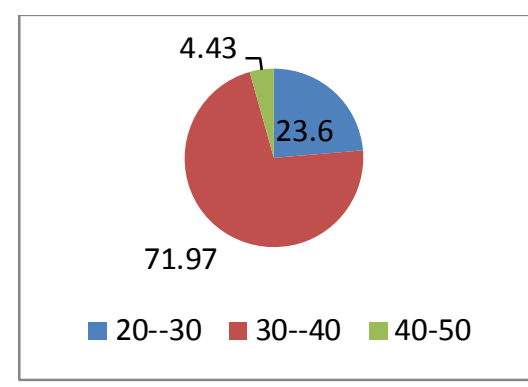

Age

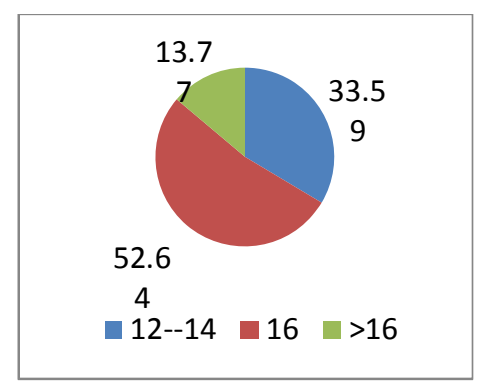

Years of education

Fig. 1. Personal characteristics of the participants

As we can observe from the results of Fig. 1, more participants in our survey were male. Besides, they were mostly middle age people and mostly university educated.

\section{The results}

In this section, we present details of our findings on testing the effects of seven organizational climate on organizational citizenship behavior. We have performed normality test using Kolmogorov-Smirnov test and determined that all data were normally distributed. Therefore, we apply Pearson correlation ratio to test the effects of various organizational climate on organizational citizenship behavior summarized in Table 1 as follows,

\section{Table 1}

The summary of Pearson correlation between organizational climate and organizational citizenship behavior

\begin{tabular}{llccc}
\hline Hypothesis & The relationship & r & Sig. & Result \\
\hline 1 & Risk taking and organizational citizenship behavior & 0.283 & 0.005 & Confirmed \\
2 & Organizational commitment and organizational citizenship behavior & 0.409 & 0.001 & Confirmed \\
3 & Reward and promotion and organizational citizenship behavior & 0.331 & 0.000 & Confirmed \\
4 & Team work and organizational citizenship behavior & 0.320 & 0.001 & Confirmed \\
5 & Organizational structure and organizational citizenship behavior & 0.437 & 0.005 & Confirmed \\
6 & Organizational communication and organizational citizenship behavior & 0.462 & 0.003 & Confirmed \\
7 & Organizational conflict and organizational citizenship behavior & -0.248 & 0.007 & Rejected \\
\hline
\end{tabular}

The results of Table 1 show that organizational citizenship behaviormaintains positive and strong correlations with risk taking $(\mathrm{r}=0.283$, Sig. $=0.000)$, organizational commitment $(\mathrm{r}=0.409$, Sig. $=$ $0.000)$, reward and promotions $(\mathrm{r}=0.331$, Sig. $=0.000)$, team-work $(\mathrm{r}=0.320$, Sig. $=0.000)$, organizational structure $(\mathrm{r}=0.437$, Sig. $=0.000)$, organizational communication $(\mathrm{r}=0.462$, Sig. $=$ $0.000)$. However, there is no meaningful relationship between organizational conflict and organizational citizenship behavior. We have performed a stepwise regression analysis between organizational citizenship behavioras dependent variable and organizational climate components as independent variables and the results are summarized in Table 2 as follows,

Table 2

The summary of stepwise regression model

\begin{tabular}{cccccc}
\hline Variables & Coefficient & Standard error & Standard coefficient & t-value & Sig. \\
\hline Intercept & 71.480 & 3.824 & & 18.985 & 0.000 \\
Organizational structure & 0.586 & 0.215 & 0.309 & 3.582 & 0.000 \\
Organizational commitment & 0.539 & 0.183 & 0.263 & 3.940 & 0.0013 \\
Team work & 0.501 & 0.127 & 0.211 & 3.716 & 0.0002 \\
\hline
\end{tabular}


The results of Table 2 indicate that organizational citizenship behavior has positive relationship with organizational structure $(\beta=0.586)$, organizational commitment $(\beta=0.539)$ and team work $(\beta=$ $0.501)$.

\section{Conclusion}

In this paper, we have presented a study on the relationship between organizational climate and organizational citizenship behavior. Using an existing questionnaires for organizational climate and organizational citizenship behavior, the survey has concluded that organizational citizenship behavior had positive relationship with organizational structure, organizational commitment and team work. The results of this survey are some what consistent with earlier findings reported by Arabac1 (2010), Boiral (2009) and Podsakoff et al. (2000).

\section{Acknowledgement}

The authors would like to thank the anonymous referees for constructive comments on earlier version of this paper.

\section{References}

Allen, D. K. (2003). Organisational climate and strategic change in higher education: Organisational insecurity. Higher Education, 46(1), 61-92.

Arabac1, I. B. (2010). Academic and administration personnel's perceptions of organizational climate (Sample of Educational Faculty of Firat University). Procedia-Social and Behavioral Sciences, 2(2), 4445-4450.

Boiral, O. (2009). Greening the corporation through organizational citizenship behaviors. Journal of Business Ethics, 87(2), 221-236.

Chiaburu, D. S., \& Baker, V. L. (2006). Extra-role behaviors challenging the status-quo: Validity and antecedents of taking charge behaviors. Journal of Managerial Psychology, 21(7), 620-637.

Chiang, C. F., \& Hsieh, T. S. (2012). The impacts of perceived organizational support and psychological empowerment on job performance: The mediating effects of organizational citizenship behavior. International Journal of Hospitality Management, 31(1), 180-190.

Koster, F., \& Sanders, K. (2006). Organisational citizens or reciprocal relationships? An empirical comparison. Personnel Review, 35(5), 519-537.

Korkmaz, T., \& Arpac1, E. (2009). Relationship of organizational citizenship behavior with emotional intelligence. Procedia-Social and Behavioral Sciences, 1(1), 2432-2435.

Matiaske, W., \& Weller, I. (2007). Do extrinsic rewards enhance organizational citizenship behavior? A study of public sector organizations. In Public governance and leadership (pp. 513-534). DUV.

Organ, D. W., \& Ryan, K. (1995). A meta-analttic review of attitudinal and dispositional predictors of organizational citizenship behavior. Personnel psychology, 48(4), 775-802.

Podsakoff, P. M., MacKenzie, S. B., Paine, J. B., \& Bachrach, D. G. (2000). Organizational citizenship behaviors: A critical review of the theoretical and empirical literature and suggestions for future research. Journal of Management, 26(3), 513-563.

Raub, S. (2008). Does bureaucracy kill individual initiative? The impact of structure on organizational citizenship behavior in the hospitality industry. International Journal of Hospitality Management, 27(2), 179-186.

Wang, C. L., \& Ahmed, P. K. (2004). The development and validation of the organisational innovativeness construct using confirmatory factor analysis. European Journal of Innovation Management, 7(4), 303-313. 